\title{
Determinants of perceived choice, number of options, and perceived time in making a selection*
}

\author{
JOHN H. HARVEY \\ Vanderbilt University, Nashville, Tennessee 37240 \\ and \\ JERALD M. JELLISON \\ University of Southern California, Los Angeles, California 90007
}

\begin{abstract}
An experiment was conducted to investigate the effects of number of choice options and perceived time taken to make a selection upon perceived choice. College students were asked to make a selection from a set of options which varied in numerosity; after making their selection, they were given information which varied their perception of time in making the selection. As predicted, perceived choice was found to be greater (1) the greater the number of options when a person perceived that he had taken a relatively short time; (2) if the selection involved a moderately large number of options than if it involved either a small or a very large number when a person perceived that he had taken a relatively long time; (3) the longer the time a person thought he had taken, except when the selection involved a very large number of options--in which case, perceived choice was greater the shorter the perceived time. The experiment also provided evidence about the relationship between perceived choice and perceived competence.
\end{abstract}

A relatively new line of research in the area of decision-making processes concerns the conditions affecting perceived choice in making a decision. This work is distinct from more traditional research on decision or choice behavior (Luce, 1959; Restle, 1961; Tversky, 1972) in its focus upon the individual's phenomenal experience of freedom of choice. The present investigation sought to extend previous research on determinants of this experience to include the variable of number of choice options.

The perception of choice has been considered an important variable in such major social psychological approaches as dissonance theory (Brehm \& Cohen, 1962; Zimbardo, 1969), attribution theory (Heider, 1958; Jones \& Davis, 1965; Kelley, 1967; de Charms, 1968), and reactance theory (Brehm, 1966). Only recently, however, has research been undertaken to explore the determinants of perceived choice. Studies by Harvey and Johnston (1973), Jellison and Harvey (1973), and Harvey and Harris (in press) have examined a number of variables which influence perceived choice. The principal theoretical basis for a large part of this research was an analysis of perceived choice by Mills. ${ }^{1}$

In his analysis of perceived choice, Mills suggests that choice in taking an action will be perceived to the extent that an alternative action is perceived to exist. Given one action, which will be referred to as the preferred action, another action will be perceived as an alternative if it satisfies two conditions. First, the expected outcome of the other action must be perceived to be different in

*Thanks are extended to Yvette Harvey for her help in the preparation of this paper. Requests for reprints should be sent to John H. Harvey, Department of Psychology, Vanderbilt University, Nashville, Tennessee 37240. attractiveness from the expected outcome of the preferred action. If it is not possible to differentiate between the outcome of the other action and the outcome of the preferred action, then the other action will not be perceived as an alternative and perceived choice will be minimal. Second, there must be some likelihood that the other action will lead to a more desirable outcome than the preferred action. If there is no uncertainty about whether the preferred action will lead to the more desirable outcome, then the other action will not be perceived as an alternative and perceived choice will be minimal.

Evidence supporting predictions based on Mills's analysis is provided in studies by Harvey and Johnston (1973) and Jellison and Harvey (1973). The results of these studies showed that perceived choice was greater (1) when there was a small difference in attractiveness of the possible actions than when there was a large difference and (2) when a person was uncertain about the attractiveness of each outcome than when he was certain. Both of these effects were interpreted in terms of uncertainty; for the former, it was assumed that uncertainty would be greater when there was a small difference than when there was a large difference. Further, in line with the assumption that there must be a discernible difference between the options in order for choice to be perceived, Harvey and Johnston found some evidence that perceived choice will be less when there is no difference in attractiveness between outcomes of possible actions than when there is a small difference.

In general, the greater the number of possible options from which a person can make a selection, the greater should be his perception of choice. Perceived choice 
should be enhanced because the greater the number of possibilities, the greater should be the uncertainty about whether the preferred action is the best one. However, perceived choice may not always be a direct function of the number of options. Under certain conditions, a person may perceive relatively little choice when there are a very large number of options. The present study was designed to investigate situations in which this might occur.

This experiment examined the effect upon perceived choice of number of options and perceived time taken to make a selection. It was assumed that (1) perceived time would serve as a cue informing the individual about the extent to which he had experienced uncertainty in considering the options and (2) that uncertainty would be directly related to perceived choice except when it implied to the individual that his processing ability had been taxed in considering the options. Some evidence related to these assumptions was obtained by Harvey and Johnston (1973). They found that, in a decision situation involving two options, perceived choice is greater the longer the perceived time taken to make a selection. Presumably, the sense of uncertainty produced by perceived time is not restrictive of perceived choice in situations involving relatively few options. However, in situations involving numerous alternatives-where rapid processing of information would be at a premium-a sense of uncertainty may tend to restrict perceived choice.

The following hypotheses concerning perceived choice were tested in this experiment. (1) Perceived choice will be greater the greater the number of options when a person perceives that he took a relatively short time to make a selection. (2) Perceived choice will be greater if the selection involves a moderately large number of options than if it involves either a small or a very large number when a person perceives that he took a relatively long time to make a selection. (3) Perceived choice will be greater the longer the time a person thinks he took to make a selection, except when the selection involves a very large number of options-in which case, perceived choice should be greater the shorter the perceived time.

Another purpose of this experiment was to provide a further test of the relationship between perceived choice and perceived competence which was examined in the study by Jellison and Harvey (1973). In that study it was assumed that conditions of high perceived choice provide the individual with greater opportunity to learn about and exercise his ability to manipulate, compare, and analyze information than do conditions of low perceived choice. Based on that assumption, it was predicted that individuals would report they received more information about their ability and would feel more competent in taking an action in the conditions in which perceived choice was high than in the conditions in which perceived choice was low. The results of that study provided evidence in support of those predictions and revealed a significant positive correlation between perceived choice and perceived competence. In the present study, perceived competence was again measured, and it was predicted that the experimental variables would affect perceived competence in the same manner that they were expected to affect perceived choice.

\section{METHOD}

\section{Overview}

After receiving information about a number of football teams, college men and women selected the best team from the set and then answered questions concerning their perception of choice in making the selection and their perception of competence as a consequence of making the selection. Ss received information about 3 teams (small number conditions), 6 teams (moderately large number conditions), or 12 teams (very large number conditions). Ss were told either that they had taken a relatively long time in making their selection (long time conditions) or that they had taken a relatively short time (short time conditions). In all, there were six experimental conditions comprising a 3 by 2 design.

\section{Subjects}

The Ss were 53 male and 31 female college students who participated in order to fulfill a requirement in general psychology. Only individuals having a general knowledge of football were solicited to participate in the experiment. Ss were run in individual sessions and were randomly assigned to the experimental conditions. There were $14 \mathrm{Ss}$ in each of the six conditions.

\section{Procedure}

At the beginning of each session, the $E$ told the $S$ that the study was concerned with how people make life-like decisions, namely, picking a football team for a bowl game. The $\mathrm{E}$ explained that, based on information the $S$ would be given about college football teams, his or her task was to select the best team to play in the game. He stated that the teams were actual teams considered by a particular bowl committee to play against a certain conference's representative a few years back and that all of the teams were having very successful seasons. The $E$ explained that the teams' names were not given because such information alone might influence the S's decision. He gave the $S$ a sheet of instructions which stated:

"The information you will be given is in the form of evaluative ratings of the teams on a number of performance categories. This information is provided in most football scouting reports. The football scouting report serves as a primary source of information for those persons on bowl selection committees whose responsibility it is to evaluate teams on relatively technical performance categories. Other members of the bowl selection committee may, for example, have the responsibility of evaluating teams for their television appeal or for their ability to draw fans from the nearby geographical areas. But your job is to assume the role of the committee member who is evaluating the teams on performance categories. You will be given a condensed report for each team. In your role you should try to make your selection as precisely and objectively as you can, given the information that you have. Please do not try to make a long-shot selection based on intuition."

The $S$ was then given a list of the categories included in the condensed scouting report with one-sentence descriptions of the kinds of performance covered by each category. Beside each category was an importance rating that supposedly represented how important most coaches thought the particular category was relative to other categories. The categories and their respective ratings were as follows: (1) rushing (very important), (2) passing (very important), (3) blocking (very important), (4) defense 
against rush (very important), (5) defense against pass (very important), (6) tackling (very important), (7) punting (important), (8) field goal kicking (important), (9) kicking off (important), (10) defensive substitutes (important), (11) offensive substitutes (important), (12) specialty teams (important).

On a sheet accompanying the category descriptions were instructions on use of the scouting reports. The instructions stated in part: "For each category listed in the scouting report for a team are ratings which were made by two scouts (labeled ' $A$ ' and ' $B$ '). Both of the scouts are excellent and are equally good at their job of rating teams. The ratings were made on a 7-point scale from 1 (very weak) to 7 (very strong).... An overall indication of how good a team is on a particular category may be determined by taking an average of the two scouts' ratings on the category."

The $\mathrm{E}$ then gave the $\mathrm{S}$ his or her scouting reports and emphasized that he or she should take into account how important each category was and the ratings for each category in making his or her decision. Each scouting report consisted of a xeroxed page with the category ratings for a particular team.

In all conditions, Team $L$ had a higher overall average rating than the other teams for the very important categories. Team L's overall average rating for the six very important categories for Scout A was 6.1 and for Scout B was 6.1. Some of the remaining teams (each designated by a particular letter) had an overall average rating of 5.8 for Scout A and 5.7 for Scout B, and the other remaining teams had an overall rating of 5.7 for Scout $A$ and 5.8 for Scout $B$.

In all conditions, Team $L$ had a lower overall average rating than the other teams for the important categories. Team L's overall average rating for the six important categories for Scout A was 5.8 and for Scout B was 5.5. Some of the remaining teams had an overall average rating of 6.0 for Scout $A$ and 5.6 for Scout $B$, and the other remaining teams had an overall average rating of 6.1 for Scout A and 5.5 for Scout B.

Therefore, in all conditions, Team $\mathrm{L}$ was slightly superior to the other teams due to its overall average rating for the very important categories, and this superiority was not offset by Team L's lower overall average for the important categories. Further, all of the teams other than $L$ were virtually equal in their overall average ratings for both the very important and the important categories.

In the small number conditions, the $S$ received information about Team $L$ and two additional teams. In the moderately large number conditions, the $S$ received information about Team $L$ and five additional teams. In the very large number conditions, the $S$ received information about Team $L$ and 11 additional teams.

In the short time conditions, the $\mathrm{E}$ informed the $\mathrm{S}$ immediately after completion of the evaluation of the teams that he or she had taken half as long as most people do on the task In the long time conditions, the $\mathrm{E}$ informed the $\mathrm{S}$ immediately after completion of the evaluation of the teams that he or she had taken $1 \frac{1}{2}$ times as long as most people do on the task. In al conditions, the $E$ reemphasized the point about how long the $S$ had taken just prior to the S's answering of the dependent variable questions.

The actual amount of time taken by each $S$ in evaluating the teams was recorded by the $\mathrm{E}$.

In introducing the questions designed to measure the variables of interest, the $E$ explained to the $S$ that he or she would be asked some questions concerning subjective feelings about making the decision. The questions were presented in a booklet and the first question was "Which team did you select?" Each of the remaining six questions was answered on a scale from 0 to 20. These questions and the labels on the respective end points of the scale were: "How much choice did you feel in deciding which team to select?" (none at all-a very large amount); "As a result of making this football selection, how competent do you feel you are at making decisions about the relative quality of
Table 1

Means for the Measure of Perceived Choice

\begin{tabular}{cccc}
\hline \multirow{2}{*}{$\begin{array}{c}\text { Perceived Time } \\
\text { in Making } \\
\text { Selection }\end{array}$} & \multicolumn{3}{c}{ Number of Options } \\
\cline { 2 - 4 } & Small & $\begin{array}{c}\text { Moderately } \\
\text { Large }\end{array}$ & $\begin{array}{c}\text { Very } \\
\text { Large }\end{array}$ \\
\hline Short & 4.6 & 8.4 & 13.9 \\
Long & 6.7 & 11.2 & 8.3 \\
\hline
\end{tabular}

Note-The higher the score, the greater the perceived choice.

top-notch teams?" (not at all-extremely); "As a result of making this football selection, how much information did you gain about your ability to make decisions about the relative quality of top-notch teams?" (none at all-a very large amount); "How much did you enjoy the process of deciding what team to select?" (not at all-extremely); "How complex was the problem of selecting a team?" (not very-extremely); "How much effort did you expend in making your selection?" (very little-a very large amount).

\section{Perceived Choice}

\section{RESULTS}

Perceived choice was hypothesized to be greater (1) the greater the number of options when a person perceives that he took a relatively short time to make a selection, (2) if the selection involves a moderately large number of options than if it involves either a small or a very large number when a person perceived that he took a relatively long time to make a selection, (3) the longer the time a person thinks he took to make a selection, except when the selection involves a very large number of options-in which case, perceived choice will be greater the shorter the perceived time. Inspection of Table 1, which presents the means for the measure of perceived choice, shows that the means were in line with these hypotheses. An analysis of variance for the six conditions showed a significant interaction of Number of Options by Perceived Time $(\mathrm{F}=10.2, \mathrm{df}=2 / 78$, $\mathrm{p}<.01)$. This analysis also revealed that the main effect for number of options was significant $(F=14.3$, $\mathrm{df}=2 / 78, \mathrm{p}<.01)$. The main effect of perceived time did not approach significance.

Newman-Keuls tests on differences among means revealed that the mean for the short time/moderately large number condition was significantly greater than the mean for the short time/small number condition and was significantly less than the mean for the short time/very large number condition ( $p s<.01$ ). The mean for the long time/moderately large number condition was significantly greater than the mean for the long time/small number condition $(p<.01)$. The difference between the mean for the long time/moderately large number condition and the mean for the long time/very large number condition did not reach a conventional level of significance. The mean for the long time/very large number condition was significantly less than the mean for the short time/very large number condition $(p<.01)$. For both the small and moderately large number conditions, the long time condition was significantly greater than the short time condition 
Table 2

Means for the Measures of Perceived Competence

\begin{tabular}{lcccccccc}
\hline & \multicolumn{5}{c}{ Short } & & \multicolumn{3}{c}{ Lerceived Time in Making Selection } \\
& $\begin{array}{c}\text { Small } \\
\text { Number }\end{array}$ & $\begin{array}{c}\text { Moderately } \\
\text { Large Number }\end{array}$ & $\begin{array}{c}\text { Very Large } \\
\text { Number }\end{array}$ & & $\begin{array}{c}\text { Small } \\
\text { Number }\end{array}$ & $\begin{array}{c}\text { Moderately } \\
\text { Large Number }\end{array}$ & $\begin{array}{c}\text { Very Large } \\
\text { Number }\end{array}$ \\
\hline $\begin{array}{l}\text { Competence in } \\
\text { making decisions }\end{array}$ & 6.2 & 9.6 & 13.1 & & 6.9 & 11.0 & 9.6 \\
$\begin{array}{l}\text { Information gained about } \\
\text { ability to make decisions }\end{array}$ & 5.5 & 7.7 & 11.6 & & 7.4 & 10.6 & 7.8 \\
\hline
\end{tabular}

Note-The higher the score, the greater the perceived competence.

(ps <.05). Overall, the results provide good support for the hypotheses for the measure of perceived choice.

\section{Perceived Competence}

It was predicted that the experimental variables would affect perceived competence in the same manner that they were expected to affect perceived choice. Means for the measures of perceived competence (i.e., the question concerning feelings of competence in making decisions and the question dealing with information about ability) are presented in Table 2 . It can be seen from Table 2 that the means for both measures of perceived competence are patterned after the means for the measure of perceived choice. In the short time conditions, perceived competence is greater the greater the number of options. For both the small and the moderately large number conditions, perceived competence is greater in the long time condition than in the short time condition, while for the very large number conditions it is less in the long time condition than in the short time condition. In the long time conditions, perceived competence is greater in the moderately large number condition than in the small number or the very large number conditions. Analyses of variance showed that the interaction of Number of Options by Perceived Time was significant for the information about ability measure $(F=5.7, d f=2 / 78$, $\mathrm{p}<.01)$ and approached significance for the measure of feelings of competence in making decisions $(F=2.6$, $\mathrm{df}=2 / 78, \mathrm{p}<.08$ ). For both measures, significant $(p<.05)$ main effects occurred for the number of options variable.

Newman-Keuls tests for the information about ability measure showed that the mean for the short time/moderately large number condition was significantly less than the mean for the short time/very large number condition $(p<.05)$ but was not significantly different from the mean for the short time/small number condition. For this same measure, the mean for the long time/moderately large number condition was significantly greater than both the mean for the long time/small number condition $(p<.01)$ and the mean for the long time/very large number condition $(p<.05)$. For both the small and moderately large number conditions, the mean for the long time condition was significantly greater than the mean for the short time condition (ps $<.05$ ). A comparison between the mean for the short time/very large number condition and the mean for the long time/very large number condition was significant $(p<.05)$. The only comparison for the measure of feelings of competence which showed a significant difference was a comparison between the short time/moderately large number condition and the short time/small number condition $(p<.05)$. These results provide qualified support for the predicted relationships between the experimental variables and perceived competence. The results for the information about ability measure provide evidence for the predictions; however, the results for the measure of feelings of competence in making decisions provide only directional support for the predictions.

Based on previous research (Jellison \& Harvey, 1973), it was expected that there would be a positive relationship between perceived choice and perceived competence. Correlational analyses revealed a significant positive correlation between the overall ratings of perceived choice and the overall ratings of feelings of competence in making decisions $(r=.65, p<.01)$ and between the overall ratings of perceived choice and the overall ratings of information about ability $(r=.46$, $\mathrm{p}<.01$ ). Also, there was a significant positive correlation between the overall ratings of feelings of competence in making decisions and the overall ratings of information about ability $(r=.43, p<.01)$. The magnitude of the correlation between these variables within each experimental condition was consistently similar to the overall correlation.

\section{Perceived Effort and Perceived Complexity of Task}

It was expected that Ss would feel they had expended more effort in making the selection and that the task had been more complex, the greater the number of options and the longer the perceived time taken to make a selection. Inspection of Table 3 , which presents means for the measures of perceived effort expended and perceived complexity of the task, shows that the data are consistent with this expectation. An analysis of variance for the effort measure revealed significant main effects for the number of options available $(F=12.4$, $\mathrm{df}=2 / 78, \mathrm{p}<.01)$ and the perceived time variable 
Table 3

Means for the Measures of Perceived Effort in Making Selection and Perceived Complexity of Task

\begin{tabular}{|c|c|c|c|c|c|c|}
\hline & \multicolumn{2}{|r|}{ Short } & Perceived Time in & Making Selection & Long & \multirow[b]{2}{*}{$\begin{array}{c}\text { Very Large } \\
\text { Number }\end{array}$} \\
\hline & $\begin{array}{c}\text { Small } \\
\text { Number }\end{array}$ & $\begin{array}{c}\text { Large } \\
\text { Number }\end{array}$ & $\begin{array}{c}\text { Very } \\
\text { Large Number }\end{array}$ & $\begin{array}{c}\text { Small } \\
\text { Number }\end{array}$ & $\begin{array}{c}\text { Moderately } \\
\text { Large Number }\end{array}$ & \\
\hline $\begin{array}{l}\text { Perceived effort in } \\
\text { making selection }\end{array}$ & 5.8 & 8.9 & 10.4 & 8.0 & 9.4 & 14.6 \\
\hline $\begin{array}{l}\text { Perceived complex- } \\
\text { ity of task }\end{array}$ & 4.3 & 6.4 & 10.3 & 5.7 & 8.4 & 12.8 \\
\hline
\end{tabular}

Note-The higher the score, the greater the amount of perceived effort or perceived complexity, respectively.

$(\mathrm{F}=5.9, \mathrm{df}=2 / 78, \mathrm{p}<.01)$. Also, an analysis of variance for the complexity measure showed significant main effects for the number of options variable $(\mathrm{F}=23.8, \mathrm{df}=2 / 78, \mathrm{p}<.01)$ and for the perceived time variable $(\mathrm{F}=6.0, \mathrm{df}=1 / 78, \mathrm{p}<.05)$. There were no other significant effects for either of these analyses. These results indicate that perceived expenditure of effort and perceived complexity of the task increased the greater the number of options and the longer the perceived time taken to make a selection.

\section{Enjoyment of Task}

It might be proposed that Ss who felt that they had a lot of choice in making a selection and who felt that they learned a lot about their ability in making the selection would also feel that the task had been enjoyable. The results provide some support for this supposition. Means for the ratings of enjoyment are presented in Table 4 . It can be seen from Table 4 that, in general, the means for the enjoyment ratings were high in the conditions in which perceived choice and learning about ability ratings were high. The means are patterned the same for these three measures, with the exception that for the enjoyment measure the mean for the short time/moderately large number condition is slightly larger than the mean for the long time/moderately large number condition. An analysis of variance for the enjoyment measure did not show any significant effects. However, a Newman-Keuls analysis did indicate that the mean for the short time/very large number condition was significantly greater than the mean for the long time/very large number condition $(p<.05)$. Overall correlational analyses revealed slight positive correlations between perceived choice and enjoyment $(\mathrm{r}=.22$, $\mathrm{p}<.08)$ and between information about ability and enjoyment $(r=.27, p<.06)$. These results provide some Table 4

Means for the Measure of Enjoyment in Making Selection

\begin{tabular}{cccc}
\hline $\begin{array}{c}\text { Perceived } \\
\text { Time in } \\
\begin{array}{c}\text { Making } \\
\text { Selection }\end{array}\end{array}$ & \multicolumn{3}{c}{ Number of Options } \\
\cline { 2 - 4 } & Small & $\begin{array}{c}\text { Moderately } \\
\text { Large }\end{array}$ & $\begin{array}{c}\text { Very } \\
\text { Large }\end{array}$ \\
\hline Short & 10.4 & 13.4 & 14.9 \\
Long & 10.6 & 12.5 & 11.5 \\
\hline
\end{tabular}

Note-The higher the score, the greater the enjoyment. evidence that feelings of enjoyment tended to be positively related to perceived choice and perceived gain in information about ability.

\section{Actual Time}

The actual amount of time spent by each $S$ in evaluating the teams was recorded by the $\mathrm{E}$. An analysis of variance for the actual time data revealed a significant main effect for the number of options variable $(F=51.6, d f=2 / 78, p<.001)$ but no other significant effects. The mean for the very large number conditions combined ( $\overline{\mathrm{X}}=25 \mathrm{~min} 12 \mathrm{sec}$ ) was significantly greater $(p<.03)$ than the mean for the moderately large number conditions combined $(\bar{X}=21 \mathrm{~min} 45 \mathrm{sec})$, which was significantly greater $(p<.01)$ than the mean for the small number conditions combined $(\bar{X}=15 \mathrm{~min}$ $36 \mathrm{sec})$. These results indicate that, as would be expected, actual length of time taken to make a selection was affected by the number of options but was not related to the manipulation of perceived time.

Finally, it should be mentioned that there were no significant differences among conditions in terms of which team was selected. It will be recalled that for all conditions Team $L$ was the superior in the selection. The largest number of Ss who selected teams other than Team L for any one condition was three (which occurred in both of the very large number conditions).

\section{DISCUSSION}

The results of this experiment provide strong support for the hypotheses for the measure of perceived choice. They reveal that the variable of perceived time in making a selection interacts with number of options to influence perceived choice. Essentially, they indicate that perceived choice is greater the greater the number of options when the individual feels that he has expeditiously evaluated the options; whereas, an intermediate number of options produces a relatively great amount of perceived choice when the individual feels that he has taken a rather lengthy amount of time in evaluating the options. The results also show that the relationship between perceived choice and perceived time is generally linear but that, when the choice situation involves a very large number of options, the 
relationship is inverse. Overall, these results provide an important contribution to the literature on determinants of perceived choice. Although in common-sense psychology perceived choice often is defined in terms of number of options, there have been few if any previous investigations designed to examine systematically the effect of number of options on perceived choice.

The results for the measures of perceived competence provide some support for the predictions that Ss would report they had received more information about their ability and would feel more competent about making decisions in the situations in which they perceived high choice than in the situations in which they perceived low choice. The results were significant for the measure of information about ability but were only marginally significant for the measure of feelings of competence in making decisions. The present reasoning suggests that an individual has maximal opportunity to learn about and exercise his ability to deal with information in high perceived choice situations. Interestingly, the finding of greater perceived competence in the long time/moderately large number condition than in the long time/very large number condition suggests that the greater informative value of relatively high choice situations is maintained even when the relatively low choice situations are rather complicated and may as such be challenging to an individual's processing ability.

A potentially important implication follows from the results for the perceived enjoyment measures. Although these results were not significant, they do show trends toward greater enjoyment in the conditions where perceived choice and perceived gain in information about ability were high. These results suggest that decision situations which embody high perceived choice and which provide an opportunity to gain competence information may be rewarding to the individual and, as such, may elicit a relatively high level of motivation to engage in the same or similar activities in the future. Further research is necessary to explore these possibilities.

\section{REFERENCES}

Brehm, J. W. A theory of psychological reactance. New York: Academic Press, 1966.

Brehm, J. W., \& Cohen, A. Explorations in cognitive dissonance. New York: Wiley, 1962.

de Charms, R. Personal causation: The internal affective determinants of behavior. New York: Academic Press, 1968.

Harvey, J. H., \& Harris, B. Determinants of perceived choice and the relationship between perceived choice and expectancy about feelings of internal control over own behavior. Journal of Personality \& Social Psychology, in press.

Harvey, J. H., \& Johnston, S. Determinants of the perception of choice. Journal of Experimental Social Psychology, 1973, 9, 164-179.

Heider, F. The psychology of interpersonal relations. New York: Wiley, 1958.

Jellison, J. M., \& Harvey, J. H. Determinants of perceived choice and the relationship between perceived choice and perceived competence. Journal of Personality \& Social Psychology, $1973,28,376-382$.

Jones, E. E., \& Davis, K. E. From acts to dispositions. In L. Berkowitz (Ed.), Advances in experimental social psychology. Vol. 2. New York: Academic Press, 1965.

Kelley, $H$. H. Attribution theory in social psychology. In $D$. Levine (Ed.). Nebraska symposium on motivation. Lincoln, Nebr: University of Nebraska, 1967.

Luce, R. D. Individual choice behavior: A theoretical analysis. New York: Wiley, 1959.

Restle, F. Psychology of judgment and choice. New York: Wiley, 1961.

Tversky, A. Elimination by aspects: A theory of choice. Psychological Review, 1972, 79, 281-299.

Zimbardo, P. G. The cognitive control of motivation Glenview, Ill: Scott, Foresman, 1969.

\section{NOTE}

1. Personal communication, 1970.

(Received for publication December 10, 1973; revision received January 19,1974 .) 